\title{
Databases and their Employment in the Flipped Classroom Learning Environment at Saudi Universities
}

\section{Waleed Tageldin Elsigini ${ }^{1}$ Hanaa Abdulraheem Yamani ${ }^{2}$ (D)}

'Assistant Prof. E-Learning Education Faculty, Mansoura University, Egypt; Umm Al-Qura University, Saudi Arabia.

Email:retelsigini@uqu.edu.sa Tel:00966500577314

'Assistant Prof. Computer Science (E-Learning) Umm Al-Qura University, Saudi Arabia.

Email:havamani@uqu.edu.sa Tel:00966566655763

\begin{abstract}
The use of technology in education has become an urgent necessity and is no longer a luxury. This is evident through the attachment of students to their tablets, mobile phones, and other forms of various technologies. Therefore, educational institutions, especially universities and higher education institutions, must think according to the age variables and their requirements by providing interesting and attractive educational environments that suit the interests of students. In this context, several strategies based on the employment of modern technology have appeared in the educational process, perhaps the most prominent of which is called the flipped classroom. This paper aims to introduce a proposed model for employing databases in the flipped classroom learning environment at Saudi universities, based on the integration between database and instructional design models where the transition to a flexible and effective virtual learning environment suits the growing and changing needs of students; it also reviews the concept of the flipped classroom and its features in improving the teaching and learning process, as well as reviewing the database concept, its components, characteristics, and roles in developing the educational system.
\end{abstract}

Keywords: Flipped classroom, Databases, Instructional design, Learning environment, Instructional technology, Higher education.

Citation | Waleed Tageldin Elsigini; Hanaa Abdulraheem Yamani (2021). Databases and their Employment in the Flipped Classroom Learning Environment at Saudi Universities. Journal of Education and e-Learning Research, 8(1): 1-7.

\section{History:}

Received: 2 October 2020

Revised: 9 November 2020

Accepted: 7 December 2020

Published: 29 December 2020

Licensed: This work is licensed under a Creative Commons

Attribution 3.0 License $(\mathrm{cc}) \mathbf{E}$

Publisher: Asian Online Journal Publishing Group
Acknowledgement: Both authors contributed to the conception and design of the study.

Funding: This study received no specific financial support.

Competing Interests: The authors declare that they have no conflict of interests.

Transparency: The authors confirm that the manuscript is an honest, accurate, and transparent account of the study was reported; that no vital features of the study have been omitted; and that any discrepancies from the study as planned have been explained.

Ethical: This study follows all ethical practices during writing.

\section{Contents}

1. Introduction

2. Theoretical Framework 


\section{Contribution of this paper to the literature}

This paper contributes to enrichment of the theoretical perception about developing the flipped classroom learning environment, by proposing a guided model for embedding databases in the flipped classroom, as this contributes to the transition for a flexible and effective virtual learning environment that takes into account the increasing and changing needs of students, ultimately leading to raising the quality of graduates. In addition, it qualifies them to compete effectively in the labor market.

\section{Introduction}

The era in which we live is characterized by constant change and rapid development in all aspects of life. The scientific and technological revolution is one of the biggest changes to characterize our contemporary world, and we are witnessing its effects in various fields. Educational institutions, especially higher education, are among the most important institutions of society that have responded to this technological revolution by implementing the products of this revolution in activating its operations and achieving its goals.

The flipped classroom is considered one of the most important strategies based on the use of modern technology in the educational process, which is summarized in the learning tasks between the classroom and home environments, where the teacher invests modern technologies to prepare lessons through videos and demos that students review at home, followed by performing instructional home activities in class (Graham, 2013; Marlowe, 2012; Trucker, 2012).

The effectiveness of the flipped classroom strategy has been confirmed in developing students' achievement, attitudes, and skills in many fields and in various curricula (Al-Ghamdi \& Al-Ansari, 2018; Al-Zahrani, 2015; AlZein, 2015; Bansal, Bansal, Ahmad, \& Pandey, 2020; Nikitova, Kutova, Shvets, Pasichnyk, \& Matsko, 2020).

On the other hand. Marco (2010) stated that the flipped classroom strategy was mainly related to video technology, where educational lessons recorded using audio and video provide an alternative to the traditional lecture, which limits use of the educational video as a means of delivering content for the majority of those who applied this strategy to students. However, technological development and scientific progress in the field of computer science and its applications have provided many tools that can be used within the framework of the flipped classroom pattern.

Al-Mallah (2016) also stated that it is not natural, in light of recent technological progress, that this strategy is limited to educational videos, so we find ourselves facing an important challenge. The flipped classroom should employ information and communication technologies in activation of its role and processes.

Hwang, Yin, \& Chu (2019) stated that, at the present time, there are many studies that have already proved the effectiveness of flipped learning, and hence researchers have started to investigate whether adopting innovative technologies or strategies can make flipped learning more flexible and effective.

From the foregoing, and in light of the growing role played by databases in the development of various societal sectors, including education and learning, Deperlioglu, Sarpkaya, \& Ergun (2011) indicated that databases work to create a flexible and effective virtual learning environment geared to meeting students' growing and changing needs. Gorman (2015) emphasized the effectiveness of databases in achieving better educational outcomes for different levels of student. Horst \& Cobb, 2005) and Zahir (2009) mentioned that databases have many characteristics and capabilities that can be used in the field of teaching and learning, and also to support and develop many educational strategies.

Comerford, Mannis, DeAngelis, Kougioumtzoglou, \& Beer (2019) sought to address deficiencies in the field of the flipped classroom as a type of blended learning, by developing e-learning programs based on databases.

This paper aimed to create a proposal model for employing databases in the learning environment of the flipped classroom at Saudi universities, where these are mainly responsible for preparing individuals and human competencies able to face the information and communication technology revolution and harnessing it to advance society's progress.

\section{Theoretical Framework}

This section is concerned with reviewing the flipped classroom in terms of concept and features, as well as the relevant databases in terms of concept, features, components, and characteristics; and, finally, a proposed model for employing databases to develop the flipped classroom learning environment is reviewed.

\subsection{The Flipped Classroom}

The idea of the flipped classroom, which is one of the most important strategies based on employing modern technology in the educational process, revolves around the core of traditional learning concepts used to explain lessons by a faculty member in the lecture setting, as the faculty member invests modern technologies to prepare lessons and also through videos and demos. Each student reviews them at home according to their abilities and capabilities, and then carries out the activities that were scheduled for home in the lecture (Al-Ruwais, 2016; Graham, 2013; Marlowe, 2012; Trucker, 2012).

Several studies have researched the effectiveness of the flipped classroom in enhancing the learning process, including Al-Zahrani (2015), who concurred with the effectiveness of the flipped classroom in developing the cognitive achievement skills of postgraduate students regarding social studies at King Saud University in Saudi Arabia; the study of Al-Zein (2015), which confirmed the effectiveness of the flipped class in developing the academic achievement of students of Princess Nora bent Abdurrahman College in the Kingdom of Saudi Arabia; and the study of Al-Ghamdi \& Al-Ansari (2018), which confirmed the effectiveness of flipped learning in developing achievement and self-learning skills among first- and second-level students at Taif University in Saudi Arabia.

The study of Nikitova et al. (2020) confirmed the value of using a flipped classroom model supported by a multimedia-based textbook, entitled Ukrainian Language (for Professional Purposes), for the language proficiency of university students in language and literature teaching; the results revealed a greater desire to engage independently with computer-assisted work, increased motivation 
to study, quicker problem solving, improved time management, and lifelong learning skills. A study by Bansal et al. (2020) indicated that the flipped classroom is a preferred instructional approach for student learning and represents a tool for improving learning outcomes, primarily of lower-performing students on difficult concepts.

We have reviewed studies by Herreid \& Schiller (2013), Al-Sherman (2015), Al-Zein (2015), Alten, Phielix, Janssen, \& Kester (2019) and Stratton, Chitiyo, Mathende, \& Davis (2020). The most important features of the flipped classroom include the improvement of learning outcomes compared to traditional classroom-based learning; keeping pace with the requirements and data of the digital age; encouraging the optimal use of modern technology in education; increasing interaction between teacher and students; overcoming the shortage of qualified teachers; helping students of all levels to excel, in addition to those with special needs; taking into account individual differences among students; reducing the burden of homework; using class time for additional tasks and reinforcing what students learned at home; giving students an incentive to prepare before lecture time; liberating the teaching and learning process from space and time factors; providing immediate feedback to students from teachers during lectures; and overcoming the problem of forced absence suffered by some students.

On the other hand, there are some disadvantages and challenges regarding the flipped classroom, including technical problems related to the Internet, software, etc. Negative perceptions by some students included the lack of immediate comment and the length of time videos were shown, which many students do not like because most prefer short shorter videos (Ramírez, Hinojosa, \& Rodríguez, 2014).

Taylor (2015) mentioned that flipped classes can also be exhausting for instructors with busy schedules. Further criticisms include the lack of instructor contact and the necessity for developers to possess the requisite technological skills.

Du, Fu, \& WANG3 (2014) also referred to the key disadvantages of the flipped classroom: unreliable Internet connections; increased difficulty in testing students; keeping all students at the same level; relying heavily on student motivation; and fostering a learning environment that lacks knowledge.

The key challenges impacting the efficiency of the flipped classroom can be defined as: many students are unfamiliar with the flipped classroom approach; poorly developed pre-class instructional videos may hinder the learning process; some students complain that they are unable to ask questions during pre-class activities; some teachers who were introduced to the flipped classroom did not have a good perception of the techniques or advantages of this approach; and inability to motivate and monitor students' participation (Akçayır \& Akçayır, 2018; Lo \& Hew, 2017).

These challenges can be overcome through applying innovative strategies and modern technologies (Kenney, 2019).

\subsection{Databases}

Incorporating technology into educational curricula and courses has been a key goal of librarians, instructional designers, school media professionals, and educators with the growth of the Internet and online databases, where it has become necessary to adopt these technologies in educational systems (Ebsco, 2020).

A database is an organized collection of data and information, usually with one central topic (Derclaye, 2005).

Database definitions are based on work by Date (2004), Helmy (2006) and Singh (2009); online course database definitions are based on work by McGreal (1998), Zahir (2009) and Elsigini (2012). The concept of the database in the learning environment of the flipped classroom can be defined as "a set of data stored in a specific way and connected with each other within mutual relationships, and representing the information of the educational course that students study, and allows students to deal with it on web pages to search and review any information related to the course and then make a the appropriate decision."

There are many studies confirming the effectiveness of employing databases in educational curricula, as these contribute to the development of students' achievements, attitudes, and skills in many instructional fields including academic writing, laboratory work, analysis, thinking, and technical fields. Databases also encourage students to progress along the learning process independently, and enhance learning outcomes, and these contributions are due to the ability of databases to support the processes of preservation and retrieval, allowing different levels of student to participate and challenge themselves in completing the tasks assigned to them within a framework of independence and self-reliance; to facilitate students' collaboration in classroom projects; to develop the teaching performance of the teacher by allowing him/her to follow the progress of students while providing appropriate support to each student separately; and sharing resources that are new and that can support the course content (Brinkerhoff, Klein, Brush, \& Saye, 2005; Horst \& Cobb, 2005; Mery, DeFrain, Kline, \& Sult, 2014 ; Priore Jr \& Giannini, 2007; Seyed-Abbassi, King, \& Wiseman, 2007; So, Pow, \& Hung, 2009; Wackerly et al., 2009; Zabudsky, 2000).

Comerford et al. (2019) also indicated the effectiveness of e-learning programs based on databases in improving the flipped classroom learning environment.

Horst \& Cobb (2005), Rhodes (2002), Seyed-Abbassi et al. (2007), (Zahir, 2009), Comerford et al. (2019) and Hamzah, Rizal, Purwati, \& Rukan (2019) wrote about the advantages of using databases in education. The suggested advantages of using databases in the flipped classroom environment are as follows:

A. Raising enthusiasm for learning and achieving educational goals among students and developing knowledge of modern technological skills, applied in educational institutions.

B. Giving the opportunity for different levels of student to participate in the learning process, and to do their utmost by providing considerable independence and freedom in learning.

C. Giving the opportunity and space for each student to express him/herself.

D. Providing the greatest amount of cooperation between students, and building their ideas among themselves, by giving each student the opportunity to research the response of his/her peers and to review what he/she and others wrote.

E. Improving analytical thinking skills and scientific research. 
F. Supporting the effective participation of the teacher by allowing him/her to monitor students' progress, and to provide appropriate support to each student, as well as the speed of data analysis and appropriate decision-making.

In order to prepare an effective vision of the use of databases in the flipped classroom learning environment, we should first know the elements and components of databases, which represent a system consisting of four elements (Date, 2004):

A. Data: These refer to what is actually stored in the database; note the difference between data and information, where data refers to what is actually stored in the database while information refers to the meaning of those data.

B. Hardware: This includes storage media that carry stored data and information, and devices for dealing with those media, in addition to communication networks and their components; as well as hardware and main memory processors that support the implementation of the database system's programs.

C. Software: The Database Management System (DBMS) is the most important software component of the system as a whole, being the link between the users and database so that it receives user requests then transfers them to the database and executes the required processing for these requests, thus providing users with the final results.

D. Users: Database users vary between application programmers who are responsible for the database structure according to one of the programming languages (such as Java, $\mathrm{C}++$, or any other programming language) and end users who enter the database in an interactive way through an application program, The database administrator is primarily responsible for the quality of data stored in the database, and for setting up and maintaining the mechanisms for dealing with it.

Secondly we should define the concept of data models, where Shenai (1992) stated that there are many data models describing the structure of the database and the method of organizing the data within it, in addition to the operations applied to the data; data models include the hierarchical data model, the network data model, and the relational data model.

The relational data model is the most used and the best performing. Date (2004) states that researches on databases over the past 30 years have relied on the relational model, and it can be said that the introduction of the relational model around 1969-1970 was the most important event in the field of database history.

The relational model describes a database as entity, attributes, and relationships between entities, and several database design tools apply the entity-relationship (ER) model concept (Elmasri \& Navathe, 2000).

The following is a description of the components of the relational model.

Entities and their Attributes: The main element presented by the ER model is the entity (table with columns showing fields or attributes, and rows with records), which is something based on the real world and has an independent existence, and it may have its actual existence as the student or in a conceptual existence such as the course; each entity has the characteristics that distinguish it, and an example of the student entity we find for his/her attributes such as name, address, and age; the entity has a value for each of its attributes, and the values of these attributes that describe the entity become the main part of the data stored in the database (Helmy, 2006).

There are many types of attribute, as follows (Elmasri \& Navathe, 2000; Sprouse, 2005):

A. Composite attribute versus simple: The composite attribute can be divided into smaller parts that provide more independent information - for example, the address of the student can be divided into three simple attributes (street number, street name, and area number).

B. Single-valued versus multivalued attributes: Most of the attributes have one value, such as the age of the student, but there is an attribute that has many values, such as university degree.

C. Stored versus derived attributes: In some cases, two or more attributes are related to each other - for example, age and date of birth.

D. Null values attribute: In some cases, we find that the attribute has no value and is either unknown or not applied.

E. The unique attribute. This is an attribute (or group of attributes) that does not recur and defines one case at most from the entity's states or records (primary key).

Relationships: This is the logical link or relationship between entities depending on the primary and foreign key fields (the foreign key is the use of data for one or more columns in the table referring to the primary key in another table) in the tables related to each other, and has a name given to describe the relationship between entities (Helmy, 2006). Sprouse (2005) explains the types of relationship as follows:

A. One-to-one: In this type of relationship, a record from the first table (entity) is linked to only one record from the second.

B. One to multiple: One record from the first table is linked to more than one record in the second.

C. Many-to-many: One record from the first table is linked to more than one record from the second, and it is also possible that the record from the second table is linked to more than one record in the first.

\subsection{Proposed Model for Employing Databases in the Flipped Classroom}

This is based on what Helmy (2006), Elmasri \& Navathe (2000), Date (2004) and Piña \& Sanford (2017) mentioned about database design, and also by reviewing the ADDIE model, where instructional designers and educators alike have used it as a framework in designing and developing educational and training programs (Cheung, 2016; Kurt, 2018).

It is possible to define a vision for the effective employment of databases in the learning environment of the flipped classroom at Saudi universities by following these stages:

1. Analysis.

2. Design.

3. Development.

4. Implement.

5. Evaluation.

The following is a description of each of these. 


\section{Analysis}

At this stage, the target groups of students are identified with analysis of their characteristics and needs from the database as far as possible; the database system's requirements, including hardware and software, are specified, as well as defining its purpose, studying the organization's structure and defining the operations or transactions that will be carried out on databases, such as extracting certain data or updating them.

The important step in this stage is choosing DBMS. The process of choosing a DBMS is affected by many factors, some of which are technical and some economic, and these are also affected by the institution's policies. The following factors are specified:

A. Technical factor: This relates to the suitability of the database management system for the purpose of the database, with emphasis on the storage structure of the data, the entry paths supported by the system, the interaction interfaces available to the programmer and the end user, the availability of development tools, and the possibility of interaction with other systems.

B. Organization factor: This relates to the familiarity of programmers and employees of the organization with a specific management system, and this factor is dependent on the capabilities of the management system itself in terms of the availability of a text editor, report generator, communication programs, design tools, and query tools used across the WWW.

C. Cost factor: This relates to the cost of purchasing the system, maintenance, and collection of the physical components the system deals with, including memory, storage media, system training, and operating requirements

2. Design

This stage includes two parallel activities: Conceptual Schema Design

A conceptual schema is a brief description of data and includes types of entities (tables), fields, records, and relationships between tables, without paying attention to storage details, and this diagram is used to ensure that all user requirements have been taken into account and that there are no conflicts between them; as well as taking into account the functional requirements represented in the operations that are expected to be performed on the database.

In order to understand the process of preparing the conceptual schema, one must know the following elements: A. Approaches to conceptual schema design

To design a conceptual diagram, the basic components of the diagram must be defined (tables, relationships, instructions on data within records and fields), and there are two options for designing a conceptual diagram:

- Centralized schema design approach, in which all the requirements of different applications and user groups are integrated into one template before we start to design the scheme, and this requires much effort and time.

- View integration approach, in which each schema is designed based on the requirements of each group, and these schemes are merged or integrated into a global conceptual schema, which is more acceptable and desirable for most database designers.

B. Strategies for schema design

The conceptual schema design strategies are as follows:

- Button-up strategy, where we begin with entities, their attributes, then relationships and add new relationships between entity types as the design process progresses.

- Inside-out strategy, which is a special case of the previous one where the focus is on major entities in the scheme, and we continue to add other types of entities and relationships as the design process progresses.

- Mixed strategy, which is a mixture of the two previous strategies where part of the conceptual scheme is built with the first strategy and part is built with the second, and so on until the scheme is completed.

Transaction and Application Design

Database designers are interested in the type of applications that will work on the database, and a common method for defining a transaction is to define the inputs and outputs. Transactions can be divided into three categories:

- Retrieval transactions, used to retrieve data for display or to produce a report.

- Update transactions, used to enter new data or modify existing data in the database.

- Mixed transactions, used to combine the two previous types.

In this activity, cooperation with content experts and educational designers is carried out in preparing scenarios and interfaces with which students will interact, where they review educational content and search for any information they need.

\section{Development}

At this stage we consider the practical implementation of the conceptual schema in the database management system selected, where the conceptual schema is created in the database management system. In other words, the conceptual diagram is transferred to an actual applied model in the database management system.

Next, choosing the storage structure of data, indices, and access paths for database files is done in order to achieve good efficiency for various database applications, and each management system provides various options for the organization of files and entry paths; and, in parallel, the application software and operations at the external level are developed, where programmers make connections between the database and the interface with which students deal directly. There are many factors that must be taken into account when designing a database, including:

A. Response type, which is the time between entering data to implement a specific task and the production of results; the biggest influence in this area is the database management system, knowing that there are several factors affecting response time such as system load, the operating system used, and communication tools. 
B. Space utilization, which is the storage space for database files and the paths used to access the disk (storage media), including indices and others.

C. The amount of information that is processed during transaction throughput, which means the average number of processes completed per minute; this is very important for modifying the natural design of the data based on the efficiency observed after implementation of the database system.

\section{Implementation}

After completing the previous process, the database can be implemented, which is the responsibility of the database manager as it is loaded with the data; database transactions are done by programmers and so, by loading transactions into the database, the design process ends and the database system begins to work.

\section{Evaluation}

Students at this stage will evaluate the database system implemented through a set of opinion polls and satisfaction with this system, and based on the extent of its contribution to supporting student learning and achieving the desired learning goals; based on this evaluation, we can determine whether the system as a whole has achieved its goals.

The conclusions drawn from the evaluation stage can be used for further development, or even for making decisions to make greater changes to the system.

Finally, database designers must take into account the specifications of the good design of databases, as mentioned by Grayson (2002), by avoiding excessive storage of data elements and providing adequate access to data while strengthening the preservation of data integrity through the progress of database usage. The database design should be clear and easy to understand.

\section{Recommendations}

Through the foregoing, a set of proposals and recommendations can be presented as follows:

1. Employing the proposed model of databases to develop the flipped classroom learning environment in higher education institutions.

2. Spreading awareness among faculty members about the importance of employing the latest teaching strategies and methods, based on modern technology, to develop the teaching and learning community.

3. Striving to develop available teaching strategies and methods in light of the latest studies and literature.

4. Providing the funds and human resources to create databases for the various educational courses in Saudi universities from which students can benefit, at any time and from anywhere.

5. Providing training courses for both faculty members and students on using and employing databases, and making use of them in the field of teaching and learning.

6. Holding specialized scientific conferences periodically; to determine what is new in the field of employing databases and e-courses in the educational system.

7. Encouraging innovation among the community of faculty members to employ technical innovations in the field of education, and providing financial and moral incentives for senior faculty members.

\section{Conclusion}

The use of technological innovations to support the flipped classroom environment is one of the most important modern trends to have attracted the attention of educational experts and teachers and, in this regard, a model has been proposed for employing databases in the learning environment of the flipped classroom at Saudi universities, based on integration and mixing between educational design models and database design models. It includes five stages: analysis, design, development, implementation, and evaluation. The researchers believe that being guided by this model may contribute to development of the flipped classroom learning environment, and therefore it will contribute to raising the level of graduates in Saudi universities and qualify them to compete effectively in the labor market.

\section{References}

Akçayır, G., \& Akçayır, M. (2018). The flipped classroom: A review of its advantages and challenges. Computers Eீ Education, 126, 334345.Available at: https://doi.org/10.1016/j.compedu.2018.07.021.

Al-Ghamdi, M., \& Al-Ansari, W. (2018). The effectiveness of employing the flipped learning strategy in developing self-learning skills and cognitive achievement in the social and national studies course among first-level secondary school students in Taif. International Journal of Educational Research, UAE University, 42(3), 196-263.

Al-Mallah, T. (2016). Challenges of flipped learning and techniques that open up new Horizons for it. Retrieved from: https://www.neweduc.com/\%D8\%AA\%D8\%AD\%D8\%AF\%D9\%8A\%D8\%A7\%D8\%AA-\%D8\%A7\%D9\%84\%D8\%AA\%D8\%B9\%D9\%84\%D9\%85\%D8\%A7\%D9\%84\%D9\%85\%D8\%B9\%D9\%83\%D9\%88\%D8\%B3-\%D9\%88\%D8\%A3\%D8\%AF\%D9\%88\%D8\%A7\%D8\%AA\%D9\%87.

Al-Ruwais, A. (2016). Flipped learning in university education. Afaq Journal, Saudi Society for Educational and Psychological Sciences - Justin, Riyadh, $49(130), 37-38$.

Al-Sherman, A. A. H. (2015). Blended learning and flipped learning. Amman - Jordan: Dal Al- Massira for Publishing and Distribution.

Al-Zahrani, A. (2015). The effectiveness of the flipped classroom strategy in developing the level of cognitive achievement of the e-learning course for students of the college of education at king Abdul Aziz University. Journal of the College of Education at Al-Azhar University, 126(1), 1-30.

Al-Zein, H. b. A. (2015). The effect of using the flipped learning strategy on the achievement of students of the college of education at Princess Noura bint Abdulrahman University. The International Journal of Specialized Education, Jordan, 4(1), $171-183$.

Alten, D., Phielix, C., Janssen, J., \& Kester, L. (2019). Effects of self-regulated learning prompts in a flipped history classroom. Educational Research Review, 28(2019), 1-18.

Bansal, S., Bansal, M., Ahmad, K., \& Pandey, J. (2020). Effects of a flipped classroom approach on learning outcomes of higher and lower performing medical students: A new insight. Advances in Educational Research and Evaluation, 1(1), 24-31.

Brinkerhoff, J. D., Klein, J. D., Brush, T., \& Saye, J. W. (2005). The effects of advisement and small groups on learning from a multimedia database. International Journal of Instructional Media, 32(4), 409-420.

Cheung, L. (2016). Using the ADDIE model of instructional design to teach chest radiograph interpretation. Journal of Biomedical Education, $2016(2), 1-6$. 
Comerford, L., Mannis, A., DeAngelis, M., Kougioumtzoglou, I., \& Beer, M. (2019). Utilising database-driven interactive software to enhance independent home-study in a flipped classroom setting: going beyond visualising engineering concepts to ensuring formative assessment. European Journal of Engineering Education, 43(4), 522-537.

Date, C. (2004). An introduction to database systems (8th ed.). Canada: Pearson Education Inc.

Deperlioglu, O., Sarpkaya, Y., \& Ergun, E. (2011). Development of relational database for learning management system. The Turkish online Journal of Education Technology, $10(4), 107-120$.

Derclaye, E. (2005). What is a database? The Journal of World Intellectual Property, 5(6), $981-1011$.

Du, S.-C., Fu, Z.-T., \& WANG3, Y. (2014). The flipped classroom-advantages and challenges. Paper presented at the Paper Presented at the International Conference on Economic Management and Trade Cooperation (EMTC 2014), Atlantis Press.

Ebsco. (2020). Using EBSCO databases in the k-12 classroom. Retrived from: https://connect.ebsco.com/s/article/Using-EBSCODatabases-in-the-K-12-Classroom?language=en_US.

Elmasri, R., \& Navathe, S. (2000). Fundamentals of database systems. Canada: Varsaware Inc.

Elsigini, W. (2012). Employing databases in computer simulation programs and their impact on the development of achievement for those with physics learning difficulties at the secondary stage. Journal of Education Faculty, Mansoura University, 79(1), 667-703.

Gorman., N. (2015). Why collecting student data is important to student achievement. Retrieved from: https://www.educationworld.com/a_news/why-collecting-student-data-important-student-achievement-1284123462.

Graham, B. (2013). Student perceptions of the flipped classroom. Unpublished Master Thesis, British Colombia University, Okanagan

Grayson, T. (2002). Relational database design: Database design principles. Retrieved from: https://studylib.net/doc/13651564/orelational-database-design--database-design-priciples.

Hamzah, M., Rizal, F., Purwati, A., \& Rukan, K. (2019). A review of increasing teaching and learning database subjects in computer science. Espacios, $40(26), 1-9$.

Helmy, H. (2006). Databases 1. Mansoura, Egypt: Delta Academy of Sciences.

Herreid, C. F., \& Schiller, N. A. (2013). Case studies and the flipped classroom. Journal of College Science Teaching, 42(5), 62-66.

Horst, M., \& Cobb, T. (2005). Expanding academic vocabulary with an interactive on-line database. Language Learning $\Xi^{\circ}$ Technology, 9(2), 90-110.

Hwang, G.-J., Yin, C., \& Chu, H.-C. (2019). The era of flipped learning: Promoting active learning and higher order thinking with innovative flipped learning strategies and supporting systems. Interactive Learning Environment, 27(8), 991-994.

Kenney, J. (2019). Flipped classroom: Overcoming challenges. Retrieved from https://www.chemedx.org/blog/flipped-classroomovercoming-challenges. [Accessed October. 15,2020].

Kurt, S. (2018). ADDIE model: Instructional design. Retrieved from https://educationaltechnology.net/the-addie-model-instructionaldesign/. [Accessed May 23,2020].

Lo, C. K., \& Hew, K. F. (2017). A critical review of flipped classroom challenges in K-12 education: Possible solutions and recommendations for future research. Research and Practice in Technology Enhanced Learning, 12(1), 1-22.Available at: https://doi.org/10.1186/s41039-016-0044-2.

Marco, R. (2010). Using video lectures to make teaching more interactive. International Journal of Emerging Technologies in Learning (iJET), 5(2), 45-48.Available at: https://doi.org/10.3991/ijet.v5i2.1156.

Marlowe, C. (2012). The effect of the flipped classroom on student achievement and stress. Unpublished Master Dissertation, Montana University, Australia.

McGreal, R. (1998). Tele campus on-line course database. Paper presented at the Proceeding of the Web Net 98 World Conference of the WWW, Internet and Intranet, November,7-12, Orlando.

Mery, Y., DeFrain, E., Kline, E., \& Sult, L. (2014). Evaluating the effectiveness of tools for online database instruction. Communications in Information Literacy, 8(1), 70-81.Available at: https://doi.org/10.15760/comminfolit.2014.8.1.153.

Nikitova, I., Kutova, S., Shvets, T., Pasichnyk, O., \& Matsko, V. (2020). Flipped learning methodology in professional training of future language teachers. European Journal of Educational Research, 9(1), 19-31.Available at: https://doi.org/10.12973/eu-jer.9.1.19.

Piña, A. A., \& Sanford, B. K. (2017). The ID database: Managing the instructional development process. TechTrends, 61(4), 331-340.Available at: https://doi.org/10.1007/s11528-017-0162-8.

Priore Jr, C. F., \& Giannini, J. L. (2007). Integrating bibliographic software, database searching, and molecular modeling in an introductory biology course. Journal of College Science Teaching, 36(5), 2 1-23.

Ramírez, D., Hinojosa, C., \& Rodríguez, F. (2014). Advantages and disadvantages of flipped classroom: STEM students' perceptions. Paper presented at the 7th International Conference of Education, Research and Innovation, 17-19 November, Seville, Spain.

Rhodes, S. (2002). Online databases in history cirriculum: Encouraging historical thinking skills and positive discussion. Paper presented at the Proceeding of NECC2002:National Educational Computing Conference, Jan17-19, San Antonio, Texas.

Seyed-Abbassi, B., King, R., \& Wiseman, E. (2007). The development of a teaching strategy for implementing a real-world business project into database courses. Journal of Information Systems Education, 18(3), 337-343.

Shenai, K. (1992). Introduction to database and knowledge-base systems. Singapore: General Printing Services Pte.Ltd.

Singh, B. (2009). Network security and management (2nd ed.). India: Prentic-Hall of India Pvt Ltd.

So, W. W.-M., Pow, J. W.-C., \& Hung, V. H.-K. (2009). The interactive use of a video database in teacher education: Creating a knowledge base for teaching through a learning community. Computers \& Education, 53(3), 775-786.Available at: https://doi.org/10.1016/j.compedu.2009.04.018.

Sprouse, W. (2005). Database design primer a beginners guide to creating adatabas. U.S.A: Center for Environmental Management of Military Lands, Colorado State University.

Stratton, E., Chitiyo, G., Mathende, A., \& Davis, K. (2020). Evaluating flipped versus face-to-face classrooms in middle school on science achievement and student perceptions. Contemporary Educational Technology, 11(1), 131-142.

Taylor, A. (2015). Flipping great or flipping useless? A review of the flipped classroom experiment at Coventry University London campus. Journal of Pedagogic Development, 5(3), 57-65.

Trucker, B. (2012). The flipped classroom. Online instruction at home free class time for learning. Education Next Journal, 12(2).

Wackerly, J., Janowicz, P., Ritchey, J., Caruso, M., Elliott, E., \& Moore, J. (2009). Using the Cambridge structural database to teach molecular geometry concepts in organic chemistry. Journal of Chemical Education, 86(4), 460-464.Available at: https://doi.org/10.1021/edo86p460.

Zabudsky, J. (2000). The digital curriculum database: Meeting the needs of industry and the challenge of enhanced student learning. Paper presented at the Proceeding of TEND 2000: The Technological Education and National Development Conference: "Crossroads of the New Millennium", April 8-10, Abu Dhabi, United Arab Emir.

Zahir, A.-G. (2009). E-courses: Their design, production, publishing, implementation, and evaluation. Cairo: Allam Al- Qutub. 